\title{
National Institutes of Health grant opportunities for the neurointerventionalist: preparation and choosing the right mechanism
}

\author{
Peter Kan (D) , ${ }^{1}$ Michael R Levitt (D) ,' ${ }^{2}$ William J Mack, ${ }^{3}$ Robert M Starke, ${ }^{4,5}$ \\ Kevin N Sheth, ${ }^{6}$ Felipe C Albuquerque, ${ }^{7}$ Maxim Mokin ${ }^{8}{ }^{8}$
}

${ }^{1}$ Neurosurgery, The University of Texas Medical Branch at Galveston, Galveston, Texas, USA

${ }^{2}$ Neurological Surgery, University of Washington School of Medicine, Seattle, Washington, USA

${ }^{3}$ Neurosurgery, University of Southern California, Los Angeles, California, USA

${ }^{4}$ Neurological Surgery, University of Miami Miller School of Medicine, Miami Beach, Florida, USA

${ }^{5}$ Department of Neurosurgery, University of Miami Miller School of Medicine, Miami, Florida, USA

${ }^{6}$ Department of Neurology, Yale University, New Haven, Connecticut, USA

${ }^{7}$ Department of Neurosurgery, Barrow Neurological Institute, Phoenix, Arizona, USA ${ }^{8}$ Neurosurgery, University of South Florida, Tampa, Florida, USA

\section{Correspondence to}

Dr Peter Kan, Neurosurgery, The University of Texas Medical Branch at Galveston, Galveston, TX 77555, USA; ptkan@utmb. edu

Accepted 20 October 2020 Published Online First 25 November 2020

\section{Linked}

- http://dx.doi.org/10.1136/ neurintsurg-2020-016964

\section{Check for updates}

(C) Author(s) (or their employer(s)) 2021. No commercial re-use. See rights and permissions. Published by BMJ.

To cite: Kan $\mathrm{P}$, Levitt MR,

Mack WJ, et al.

J Neurolntervent Surg

2021:13:287-289.

\section{ABSTRACT}

Objective The goal of this article is to

provide recommendations for the early career

neurointerventionalist in writing a successful grant

application to the National Institutes of Health $(\mathrm{NIH})$ and

similar funding agencies.

Methods The authors reviewed NIH rules and regulations and also reflected on their own collective experience in writing $\mathrm{NIH}$ grant proposals in the area of cerebrovascular disease and neurointerventional surgery. Results A strong proposal should address an important scientific problem where there is a gap in knowledge. The solution offered needs to be innovative but at the same time based on a strong scientific premise. The proposed research must be feasible to implement and investigate in the researcher's environment.

Conclusion Successful grant writing is critical in funding and enhancing research. The information in the article may aid in the preparation stage of grant writing for early career neurointerventionalists.

\section{INTRODUCTION}

Research, whether it be basic science, translational, or clinical, is important to the growth and success of neurointerventional surgery as a field. Our multidisciplinary group of clinicians and scientists includes pioneers who study the mechanisms of disease, invent new diagnostic modalities, produce novel devices used during interventions, and conduct trials of clinical safety and efficacy. Endovascular treatment of acute ischemic stroke and cerebral aneurysms are examples of areas that have benefited tremendously from neurointerventionalistdriven investigations and innovations. ${ }^{1-4}$

Funding is necessary to sustain research and ultimately translate innovative ideas to clinical practice. Grant writing is an essential skill to secure such funding and is especially important in the early stages of a researcher's career in transitioning to an independent investigator. Moreover, the grantwriting process also enhances the research and helps applicants understand the research process, gain knowledge in and outside the field, and develop key collaborations. ${ }^{5}$ Through a collaborative approach, grant writing and the review process help to strengthen research design, decrease the opportunities for experimental or trial failure, and reduce the possibility of repetitive studies.
Our field is fortunate to serve at the intersection of unique academic-industry and academicNational Institutes of Health (NIH) partnerships. The NIH and other federal opportunities play an important role in bringing in the broader scientific community. The NIH is often the ideal agency for scientific questions that may not be suitable for industry partnerships (eg, mechanisms of disease).

Although manuscript writing is a process that most early-career academic neurointerventionalists are familiar with, grant writing is significantly different and follows a different structure and style. The latter is characterized by a hypothesis-driven approach to address a scientific problem. ${ }^{67}$ Without formal graduate or postdoctoral training, most neurointerventionalists receive little information on grant preparation prior to their first submission. In addition, NIH proposals require a specific format that often differs from other agencies and foundations.

Guidance on writing a NIH grant proposal is relatively sparse, especially pertaining to neurointerventional subjects. ${ }^{8}$ To address potential gaps, we review the necessary preparation leading up to grant writing. In a separate review, we dissect the basic structure of a proposal per the NIH format for early-career neurointerventionalists seeking to apply for their first or early-stage grant and discuss the NIH review process that follows. ${ }^{9}$ This review serves as guidance, and it is important to consult with $\mathrm{NIH}$ requirements to obtain the most up-todate requirements. ${ }^{10}$

\section{MOVING FROM IDEA TO PROPOSAL - SHOULD I SUBMIT A GRANT?}

The decision to apply for funding should have a clear goal and directive. Obtaining external funding provides the resources (including salary support, equipment budget, and supplies) that may otherwise be unavailable for the physician-scientist. If the scientific question being asked is answerable without funding (such as through chart review or by adding experiments to an existing laboratory's work), then grant funding may not be worth the time and effort required for a successful application. However, beyond the financial support, applying for a grant has other intrinsic values to the researcher that should be considered. First, it encourages the applicant to focus carefully on the scientific idea, organize a research plan, and 
formalize objectives, thus enhancing the research before starting. Second, even a rejected grant application provides valuable unbiased feedback on both the scientific question and the approach the applicant proposes to solve it. This feedback will similarly improve the research. For these reasons, applying for funding should be considered for any physician-scientist with an interest in solving scientific problems.

Once the purpose of funding has been established, the idea itself should be considered carefully. A fundable idea should address a well-defined problem important to the granting agency where there exists a gap in knowledge. The solution offered needs to clearly address this gap in knowledge and be soundly based on a strong scientific premise with evidence from the field and from the researcher's own preliminary data (significance $=$ important problem + gap in knowledge + scientific premise). Innovation, both in concept (eg, new paradigm) and technique (eg, new methods or instruments), is equally important. A fundable proposal consists of well-structured aims with rigorous scientific methods (approach) to test a central hypothesis and defines a clear path towards successful completion of those aims, as well as one or more deliverables. Finally, a successful proposal must include a team with all the necessary expertise and resources to perform the research (investigators and environment).

\section{PREPARATION AND PLANNING}

\section{Mentors and collaborators}

After careful consideration of the research idea to be proposed and the aims to complete it, the next step is to assess the team before writing the grant. This evaluation begins with the principal investigator's (PI) self-assessment. It is important to identify the researcher's strengths, capacities, and areas where complementary skills are required. A good starting principle is never to write the grant alone. Research now addresses complex questions that require knowledge, skills, and techniques from complementary teams. In addition to gaining access to different research methods, equipment, and data, 'Team Science' also adds definite competitive strength to the grant application. For the first submission, consider including a mentor (a NIH-funded PI with an active research program in the area of interest) on the team as he or she will be a tremendous resource for questions regarding study design, grant writing, and regulatory pathways. Another important collaborator to always consider regardless of the type of research is an experienced statistician. Lack of sufficient detail and reasoning in statistical methodology (eg, power analysis/sample size calculation in both human and animal studies) is a common criticism from the reviewer.

A horizontal collaboration strategy with a multi-PI leadership structure is most common for the neurointerventionalist. ${ }^{11}$ In this model, each PI has a distinct complementary expertise (eg, surgical vs engineering vs regulatory), is responsible for a large, measurable, and equal portion of the scope of work (such as an individual aim), and contributes a significant level of laboratory equipment and personnel. In general, this structure allows a much broader scope of research and results in research of higher impact and innovation. The alternative is a vertical collaboration strategy with a PI and co-investigators (Co-Is), ${ }^{12}$ where Co-Is tend to have overlapping expertise with the PI, are responsible only for specific experiments or a single sub-aim, and provide only modest laboratory support. This is perhaps more suitable for basic scientists with a more narrow research focus. Prior to submission, a multi-PI grant team should also consider how to resolve conflicts that may arise around intellectual property (particularly relevant to the neurointerventionalist), data sharing, and authorship.

\section{Choosing a sponsor and mechanism for the neurointerventionalist}

Most institutions have a Grant Office, where funding opportunities are published monthly, separated by career and research level, categorized into NIH, Federal Non-NIH, State, Local, Foundation, and Philanthropy. This is typically a good place to start. Most NIH institutes establish specific research initiatives and priorities (often with higher funding rates) and the researcher's Grant Office can align the proposal with the appropriate Funding Opportunity Announcement (FOA), RFA (Requests for Applications), PA (Program Announcements), and Request for Proposal (RFP). Our highly subspecialized group is relatively small and young, with only a few individuals dedicating a significant amount of time and effort on what is considered 'traditional' research. Neurointerventionalists are often underrepresented on grant study sections or review committees. As a result, researchers in neurointerventional surgery often find it challenging and feel disadvantaged to have their research proposals considered and reviewed among other neurology, neurosurgery, or radiology disciplines. As a result, we recommend serving on a study section when the opportunity arises. It is also a great mechanism to gain in-depth knowledge about the review process.

NIH StrokeNet ${ }^{13}$ is a National Institute of Neurological Disorders and Stroke (NINDS)/NIH initiative to conduct phase I-III trials in stroke prevention, treatment, and recovery. So far, a very limited number of neurointerventional studies have been funded through this mechanism. NIH-NINDS is currently considering a platform to conduct multiple trials of endovascular therapy for ischemic stroke. The proposed Stroke Thrombectomy Endovascular Platform (STEP) (M Mokin, personal communication, 2020) in its final structure will likely include several modules including a registry of outcomes of endovascular therapy (EVT) in regular practice, trials to expand the indications for EVT, studies to explore novel concomitant therapies with EVT, and finally research dedicated towards improving stroke systems to facilitate rapid patient access to EVT. The Society of NeuroInterventional Surgery, the Joint Cerebrovascular Section, and the Society of Vascular and Interventional Neurology through their leadership are actively involved in STEP's structure design to provide a unique opportunity for neurointerventionalists who seek research funding in this area.

Neurointerventionalists can also pursue funding opportunities through industry-sponsored investigator-initiated studies. These are often small awards and could be compared with seed grants in terms of scope and scale of research questions that could be feasible with this type of proposals. One must be careful with the amount of input the sponsor (a specific private company, in this case) is expecting to exert on the study question, design, data collection, or interpretation of results. This could introduce bias and potentially weaken the quality of research.

Another unique funding opportunity that is important to the neurointerveniontalist is the Small Business Innovation Research (SBIR) and Small Business Technology Transfer (STTR) programs ${ }^{14}$ which encourage domestic small companies to engage in federally-funded research and development, with further potential for commercialization. Start-up projects centered around developing novel diagnostic imaging modalities of stroke or device innovations are some examples of small companies eligible for such awards. Consequently, this mechanism is especially suitable for neurointerventionalists with academic appointments working with small US-based companies for device development. The goal of the STTR program is the partnership between small businesses and non-profit research institutions, thus allowing the research institutions to dedicate a substantial amount of effort on proposals with small companies. 
Other NIH funding mechanisms are also available to the neurointerventionalist. Smaller grants are often necessary to provide funding to obtain preliminary data for larger NIH grants. An NIH R25 grant ${ }^{15}$ can provide critical early funds to develop a larger project for residents and fellows in neurosurgery, neurology, and radiology. For early-career neurointerventionalists, the NIH KO8 grant ${ }^{16}$ provides a mechanism to develop as a clinician scientist under direct mentorship. This grant is graded evenly on one's training plan, institutional setting, and research plan. The K22 grant ${ }^{17}$ is another early-career transition award to provide further mechanisms to develop basic science, translations, or clinical research experience while answering key research queries. Clinicians with a strong scientific background and preliminary results can apply for an NIH R01 grant ${ }^{18}$ directly to provide up to 5 years of research support for critical scientific questions. Additionally, NIH collaborative grants ${ }^{18}$ can supply critical funding for multiple clinicians from different areas to work together to establish research centers of excellence to focus on a specific disease entity and significant unmet clinical need.

\section{KEY PERSONNEL AND TIMING OF COMMUNICATION}

Within the Grant Office, institutional research development staff help to read, edit, and review grants. They should be engaged early on as they can help to develop a polished Specific Aims page (see below). The NIH Program Officer (PO) is the most important advocate and point-of-contact for the proposal. Before the Research Strategy is started, set up a time to discuss the Specific Aims page with the PO. He or she will verify that it aligns with the Institutes or Centers (ICs) strategic plan and can often refer you to the most appropriate funding mechanism, as well as which grant review panel (termed 'study section') is most appropriate to review the submission. Engaging the PO early is also critical to avoid problems with submission or funding consideration. For example, certain grants (such as those supporting large clinical trials) need budgetary and regulatory pre-approval prior to application, while others require a pre-submission letter of intent. The PO also serves as a great resource throughout the process and after funding is awarded.

About 6 weeks prior to the submission, the Department Chair should be notified to provide a letter of support and secure other necessary departmental resources. The researcher's administrative staff and pre-award office should also be contacted about the same time to begin putting together the submission (there are many important documents in addition to the Research Strategy). Advice from internal or outside reviewers who are actively funded and serve on study sections should be sought after you have a draft of the Research Strategy.

\section{TIMELINE FROM PLANNING TO SUBMISSION}

At the time of writing, most NIH application due dates are February 5, June 5, and October 5 of each year, with specific deadlines that may vary by application type. Most academic institutions often have internal deadlines 10 business days prior to the NIH deadline in addition. For the first submission, we recommend a 9-month timeline that covers the planning phase (first 3 months), the writing phase (4.5 months), and the submission phase (1.5 months prior to receipt date).

\section{SPECIAL CASE OF THE EARLY STAGE INVESTIGATOR}

$\mathrm{NIH}$ encourages research independence of new investigators who have not previously served as PI on any substantial grant except fellowship F awards, small research grants (R03, R15, R21, R42, and R43), training-related grants (T32, T34, T35,
T90, and D43), or mentored K awards. ${ }^{19}$ In addition, to qualify as an early stage investigator (ESI), the applicant has to have completed his or her terminal research degree or medical residency, whichever date is later, within the past 10 years. ESIs get special consideration and are significantly more likely to be funded after peer review. This is an important advantage that could make the difference between a proposal getting funded or not for the early-career neurointerventionalist. It is important to know that an early investigator will no longer have ESI status if they are a Co-PI on a substantial funded grant such as a R01.

\section{GRANT WRITING}

Grant writing is an important skill that often lacks formal training. Critical time and devotion is needed to formulate a successful proposal with appropriate editing and revisions. Many academic institutions offer exceptional grant writing classes. ${ }^{2021}$ These classes may be defined by the type of grant an applicant is working on and often require a rough draft for a grant that will be further developed within the class framework. ${ }^{20}$ Additionally, at annual meetings of the Society of Neurointerventional Surgery, Congress of Neurological Surgery, American Association of Neurological Surgery, and Society of Vascular and Interventional Neurology, grant classes or reviews are often offered to obtain further critical reviews for grant applicants.

\section{CONCLUSIONS}

Successful submissions require careful prior planning and collaboration is especially important for most of the research that the neurointerventionalist wants to pursue. We hope this brief review will serve as a helpful guide for the planning phase of the application process. Details about the actual grant structure, the submission process, and beyond are addressed in a separate article. ${ }^{9}$

Twitter Michael R Levitt @DrMichaelLevitt and Robert M Starke @Starke_ neurosurgery

Contributors PK: research collection, manuscript writing, manuscript editing, project conceptualization; ML, WJM, RMS, KNS, FCA, MM: research collection, manuscript editing.

Funding The authors have not declared a specific grant for this research from any funding agency in the public, commercial or not-for-profit sectors.

Competing interests None declared.

Patient consent for publication Not required.

Provenance and peer review Commissioned; internally peer reviewed.

\section{ORCID iDs}

Peter Kan http://orcid.org/0000-0001-6649-4128

Michael R Levitt http://orcid.org/0000-0003-3612-3347

Maxim Mokin http://orcid.org/0000-0003-4270-8667

\section{REFERENCES}

1 Guglielmi G, Viñuela F, Dion J, et al. Electrothrombosis of saccular aneurysms via endovascular approach. Part 2: preliminary clinical experience. J Neurosurg 1991;75:8-14.

2 Albers GW, Marks MP, Kemp S, et al. Thrombectomy for stroke at 6 to 16 hours with selection by perfusion imaging. N Engl J Med 2018;378:708-18.

3 Saver JL, Goyal M, Bonafe A, et al. Stent-retriever thrombectomy after intravenous t-PA vs. t-PA alone in stroke. N Eng/ J Med 2015;372:2285-95.

4 McDougall CG, Spetzler RF, Zabramski JM, et al. The Barrow ruptured aneurysm trial. J Neurosurg 2012;116:135-44.

5 Felzien LaC J. Modeling the research process. J Coll Sci Teach 2005;34:42-6.

6 Porter R. Why academics have a hard time writing good grant proposals. J Res Admin 2007; 38:37-43.

7 Sullivan D, Rohrich RJ. Discussion. A guide for writing in the scientific forum. Plast Reconstr Surg 2010;126:1763-71.

8 Langhorst DM, Svikis DS. The NIH R03 Award: an initial funding step for social work researchers. Res Soc Work Pract 2007;17:417-24. 
9 Kan P, Mokin M, Mack WJ. Strategies for writing a successful national Institues of health grant proposal for the early-career neurointerventionalist. J Neurointervent Surg 2020.

10 National Institutes of Health website. Available: http://www.nih.gov [Accessed 28 Sep 2020].

11 Multiple Principle Investigators. NIH grants and funding. Available: https://grants.nih. gov/grants/multi_pi/ [Accessed 29 Sep 2020].

$12 \mathrm{NIH}$ Grants and Funding. Glossary of NIH terms. Available: https://grants.nih.gov/ grants/glossary.htm [Accessed 29 Sep 2020].

13 NIH StrokeNet. Available: https://www.nihstrokenet.org [Accessed 29 Sep 2020].

14 NIH SBIR/STTR. Available: https://sbir.nih.gov/ [Accessed 30 Sep 2020].

15 NINDS Research Education Grant (R25) Program Awardees. NIH National Institute of Neurological Disorders and Stroke. Available: https://www.ninds.nih.gov/Funding/ Training-Career-Awards/Institutional-Awards/R25-Awardees [Accessed 28 Sep 2020].
16 NIH Research Training and Career Development. K08: mentored clinical scientist research career development award. Available: researchtraining.nih.gov/programs/ career-development/K08 [Accessed 30 Sep 2020].

17 K22: Career Transition Award. NIH research training and career development. Available: researchtraining.nih.gov/programs/career-development/K22 [Accessed 30 Sep 2020].

18 NIH Research Training and Career Development. How NIH can help you become a research scientist. Available: researchtraining.nih.gov/infographics/research-scientist [Accessed 30 Sep 2020].

19 NIH Grants and Funding. Early stage investigator policies. Available: https://grants.nih gov/policy/early-investigators/index.htm [Accessed 29 Sep 2020].

20 Leak RK, O'Donnell LA, Surratt CK. Teaching pharmacology graduate students how to write an NIH grant application. Am J Pharm Educ 2015;79:138.

21 Sonis JH, Triffleman E, King L, et al. How to write an NIH R13 conference grant application. Acad Psychiatry 2009;33:256-60. 